\title{
Successful ablation of giant condyloma acuminata in an adolescent
}

\section{Shikhar Ganjoo1, Pratiksha Mishra1, Mohinder Pal Singh Sawhney', Uma Sharma², Nitin Chhabra ${ }^{1}$}

${ }^{1}$ Department of Dermatology \& STD, Shree Guru Gobind Singh Tricentenary Medical College and Hospital, Gurugram, India, ${ }^{2}$ Department of Pathology, Shree Guru Gobind Singh Tricentenary Medical College and Hospital, Gurugram, India

Corresponding author: Shikhar Ganjoo, MD, E-mail: shikhar.ganjoo@gmail.com

\begin{abstract}
Condyloma acuminata are usually associated with persistent and recurrent infections and early surgical intervention is often required to prevent recurrences. The Buschke-Löwenstein tumor, a locally invasive, slow-growing, cauliflowerlike growth, is an example of a giant condyloma acuminatum. Herein, we report a case of sexually-acquired perianal giant condyloma acuminata in a fourteen-year-old male successfully treated by electrofulguration with radiofrequency cautery under general anesthesia in a single session with no evidence of recurrence over a follow-up period of six months.
\end{abstract}

Keywords: Giant condyloma acuminatum; sexual abuse; radiofrequency ablation

\section{INTRODUCTION}

Sexually transmitted diseases, such as genital warts, genital herpes, syphilis, human immunodeficiency virus (HIV) infection, are a worldwide health concern, with most of the patients 15 to 29 years old [1]. HPV is the most common sexually-transmitted viral pathogen [2], usually occurring in adults, but also in children, often due to sexual abuse. Four morphological variants of condyloma acuminatum are cauliflower-like growths, papular warts, keratotic warts, and flat-topped papules [3]. The Buschke-Löwenstein tumor-a rare STD characterized by verrucous lesions on the genitals and/or the perianal region-most commonly occurs due to HPV types 6 and 11 [4], and most commonly affecting adult males; although some case reports mention adult females and children [5]. Treatment modalities include an excisional biopsy, the application of podophyllin, imiquimod, electrosurgery, interferon or 5 -FU injections, and $\mathrm{CO}_{2}$ laser therapy. However, condyloma acuminata are usually associated with persistent and recurrent infections and early surgical intervention is often required to prevent recurrences.
Herein, we report a case of giant condyloma acuminata successfully ablated with radiofrequency cautery under general anesthesia.

\section{CASE REPORT}

A fourteen-year-old male presented himself to the department of dermatology with the chief complaint of a massive asymptomatic cauliflower-like growth in the perianal area persistent for the previous four months. No similar lesions were present elsewhere on the body. A clinical examination revealed a hyperkeratotic, verrucous tumor $5 \times 4 \mathrm{~cm}$ in size in the perianal area (Fig. 1). The genitals were examined and were found to be normal. On further questioning, the patient confessed to a history of a single unprotected penoanal sexual encounter with an acquaintance one year previously.

Histopathology revealed hyperkeratosis, papillomatosis, acanthosis of the stratified squamous epithelium, and koilocytic changes suggestive of condyloma acuminatum (Figs. 2a and 2b). We planned on electrofulguration

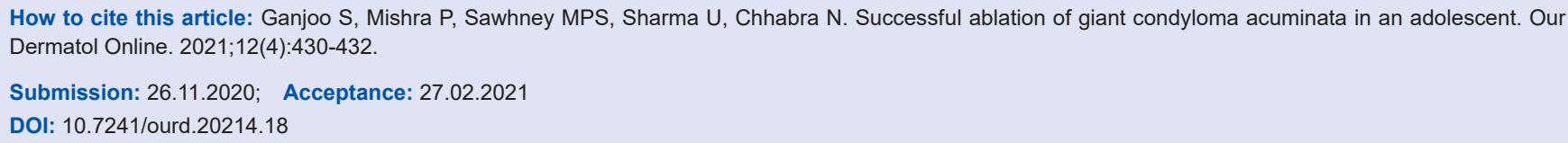




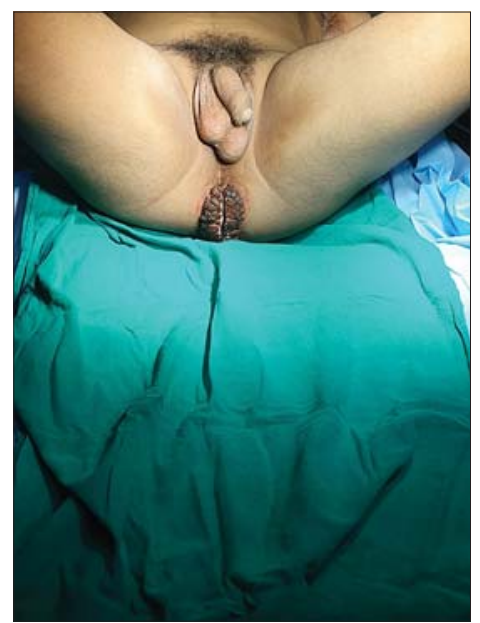

Figure 1: Hyperkeratotic, verrucous growth $5 \times 4 \mathrm{~cm}$ in size in the perianal area.

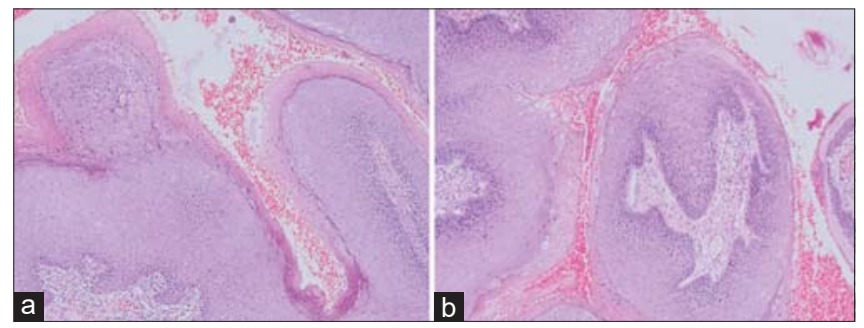

Figure 2: (a-b) Hyperkeratosis, papillomatosis, acanthosis of the stratified squamous epithelium, and koilocytic changes suggestive of condyloma acuminata (H\&E, 40x).

with radiofrequency cautery in a major operation theatre under general anesthesia (Fig. 3). A routine pre-anesthetic checkup was performed. The bowel was prepared with an enema. Post-operatively, the patient was managed with a sitz bath, topical and systemic antibiotics, laxatives, and NSAIDs. The perianal wound healed in two weeks without stricture formation or other complications (Fig. 4).

\section{DISCUSSION}

Condyloma acuminata are usually seen in younger adults [2]. Nearly half of newly contracted infections are observed in the 15-to-24-year-old age group, the average incubation period ranges from three weeks to eight months, and the physical symptoms appear approx. two to three months after the initial contact [6] Strong suspicion of sexual abuse arises in children with anogenital warts. It is, however, difficult to determine the method of HPV transmission in the pediatric population [7]. In our case, the adolescent patient was sexually abused for eight months prior to the onset of the lesion. Acrochordon, squamous cell carcinoma, and condyloma latum lie in the differential diagnosis.

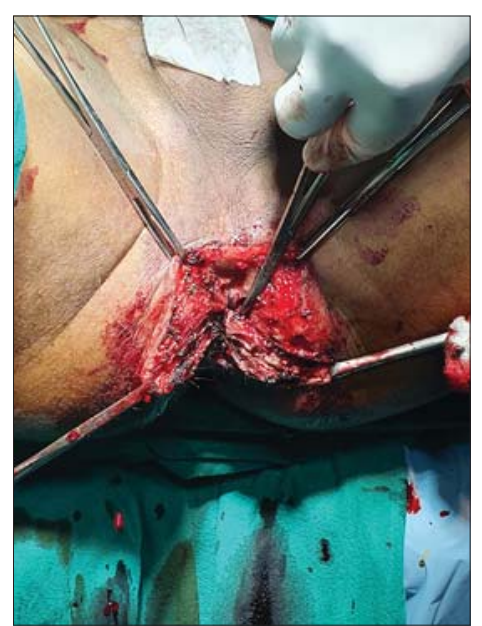

Figure 3: Intraoperative picture of the growth in the perianal area.

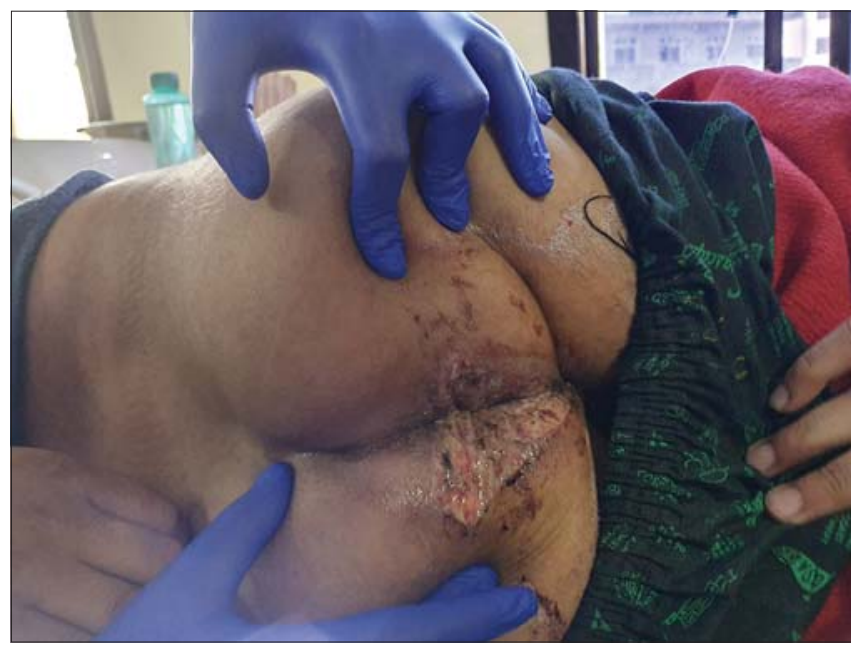

Figure 4: Postoperative picture of the wound without stricture formation or other complications.

Investigations include a PAP smear in females, a colonoscopic examination in both sexes, an HPV DNA test, and an excisional biopsy. Our case was confirmed by histopathology. Treatment includes an excision biopsy, interferon or 5-FU injections, epinephrine gel implants, the local application of podophyllin, imiquimod, curettage, electrosurgery, and $\mathrm{CO}_{2}$ laser ablation. Giant condyloma acuminata, especially in the perianal area, are difficult to treat due to the possibility of complications such as strictures and a secondary infection and because of a high recurrence rate.

Gürbulak et al. [8] performed a wide surgical excision of a large perianal condyloma acuminatum in a seventeen-year-old female, including the surrounding skin area, and the wound had to be reconstructed with a bilateral gluteal fasciocutaneous V-Y advancement flap. 
In 2013, Nambudiri et al. [9] treated a 46-yearold leukemic male with giant perianal condyloma acuminata after two unsuccessful surgical ablations with cryotherapy, a high dose of IL-2, fulguration, and topical cidofovir therapy.

Nonetheless, we were able to successfully ablate the giant perianal condyloma acuminata with radiofrequency cautery under general anesthesia, which was required to relax the anal sphincter and reveal any intra-anal extensions and to remove the entire tumor in one sitting.

\section{CONCLUSION}

Giant perianal condyloma in a child mandates thorough sexual history-taking to rule out a sexual history and abuse. As a therapeutic option, surgical ablation of the entire lesion should be attempted in one sitting.

\section{Consent}

The examination of the patient was conducted according to the principles of the Declaration of Helsinki.

The authors certify that they have obtained all appropriate patient consent forms, in which the patients gave their consent for images and other clinical information to be included in the journal. The patients understand that their names and initials will not be published and due effort will be made to conceal their identity, but that anonymity cannot be guaranteed.

\section{REFERENCES}

1. Tamer F, Yuksel ME, Avc1 E. Should patients with anogenital warts be tested for genital herpes? Initial results of a pilot study. Our Dermatol Online. 2019;10:329-32.

2. Kaderli R, Schnüriger B, Brügger LE. The impact of smoking on HPV infection and the development of anogenital warts. Int J Colorectal Dis. 2014;29:899-908.

3. Costa-Silva M, Fernandes I, Rodrigues AG, Lisboa C. Anogenital warts in pediatric population. An Bras Dermatol. 2017;92:675-81.

4. EL Jouari O, Zaougui A, Gallouj S, Farih MH, Mernissi FZ. The Buschke-Loewenstein tumor. Our Dermatol Online. 2018;9:453-3.

5. Nassiri A, Aqil N, Baybay H, Mernissi FZ, Souhli OA, Ahssaini M, et al. Extra genital HPV-6. Our Dermatol Online. 2019;10:71-3.

6. Yanofsky VR, Patel RV, Goldenberg G. Genital warts: A comprehensive review. J Clin Aesthet Dermatol. 2012;5:25-36.

7. Rizvi AA, Kanwar AJ, Goel S. Condyloma acuminata in a 3-year-old female: Sexual abuse or not? Indian J Paediatr Dermatol 2016;17:221-2.

8. Gürbulak EK, Akgün İE, Ömeroğlu S, Öz A. Giant perianal condyloma acuminatum: Reconstruction with bilateral gluteal fasciocutaneous V-Y advancement flap. Ulus Cerrahi Derg. 2015;31:170-3.

9. Nambudiri VE, Mutyambizi K, Walls AC, Fisher DC, Bleday R, Saavedra AP. Successful treatment of perianal giant condyloma acuminatum in an immunocompromised host with systemic interleukin 2 and topical cidofovir. JAMA Dermatol. 2013;149:1068-70.

Copyright by Shikhar Ganjoo, et al. This is an open access article distributed under the terms of the Creative Commons Attribution License, which permits unrestricted use, distribution, and reproduction in any medium, provided the original author and source are credited.

Source of Support: Nil, Conflict of Interest: None declared. 